\title{
Corrosion protection of embedded steel bars in concrete.
}

\author{
L., Pistolesi* and $C$., Zaffaroni
}

\begin{abstract}
The design and construction of structures is a responsible decision, based on sound engineering principles, and virtuous and cautious consideration should be paramount. This presentation is based on the results of two different field studies to protect and ensure longevity of structural reinforced steel in structural concrete.1) Application of sacrificial anodes for the galvanic cathodic protection of reinforced steel.2) Application of a cementitious polymer based elastic coating as a viable corrosion protection system against aggressive elements. The use of these materials allows the protection and increases durability of reinforcement steel in concrete, from premature degradation caused by carbonation and chloride attack, ensuring an extended life span.Sacrificial anodes for galvanic cathodic protection are composed of zinc in conjunction with electrolytic gels that, thanks to electrochemical processes, once connected with the reinforcement steel, lower the potential of corrosion to the reinforcement steel themselves. Thus, allowing the prolongation of corrosive events in structures which need to be repaired whilst preventing degradation, if correctly applied, in new structures.Furthermore, in such protection systems, a polymer-modified cementitious membrane is used, with superior elastic and crack bridge properties in environmental exposure temperatures of up to $-20^{\circ} \mathrm{C}$, thus protecting the concrete from penetration of carbon dioxide and chloride attack.Due to an in-depth laboratory study in combination with live field tests, this paper will highlight that a $2-\mathrm{mm}$ thick protection layer can effectively counteract the penetration of $\mathrm{CO}_{2}$ for over 50 years, and is comparable to a concrete cover thickness of $54 \mathrm{~mm}$ of concrete, at a w/c ratio of 0,5 . With regards to chloride attack, studies confirm that $2,5 \mathrm{~mm}$ of coating equals $30 \mathrm{~mm}$ of concrete cover at a w/c ratio of 0,452 .
\end{abstract}

\section{INTRODUCTION}

With reference to the Milan Eastern By-Pass Road, within the Milan Metropolitan territory, constructed during the mid '70s, a high-speed roadway, able to connect the major five highway sections converging to the city of Milan was constructed. The design of the Eastern By-Pass Road was quite complex due to the high density residential as well as commercial development within the construction area, and stringent legislation and restrictions established by authorities. During October 1971, the first junction of the Milan Eastern By-Pass Road was opened to traffic: the principal function of the new road network was the Viaduct "Dei Parchi" (Figure 1), an imposing structure constructed in an elevated section from Vaile Forlanini, more than 3 kilometres. The Viaduct "Dei Parchi" is one of the longest viaducts in Lombardy. It was built between 1968 and 1973 and in the '90s the extension works for an additional three driving lanes were carried out, by enlarging the internal area of the viaduct. The structure was designed as a series of frames, leaning one to the other through a Gerber saddle support. The supports are made of neoprene rubber. The underlying area of the viaduct, near the transverse joints, showed signs of corrosion. Concrete was used on the construction of the piles, and the surface deck was a pre-stressed design, both longitudinally and transversely with ample reinforcing steel. Due to the difficulty in carrying out maintenance works on a crucial and virtually inaccessible structure, a modern advanced repair method was decided on to carry out the remedial work. After diligent analysis and tests, it was decided to install a cathodic galvanic protection system on the underlying part of the joint.

\section{SCOPE}

The principal objective of this analysis was to highlight the extent of the corrosion in the reinforcement steel and to identify if the anchoring system of the pre-stressed bars were also aggressed. A half-cell potential mapping method was used to establish corrosion (probe type unknown). This is a non-destructive test through the reinforcement steel via electric potential data (expressed in millivolt) to localise possible corrosion areas. In this specific case, a total surface of $1500 \mathrm{~m} 2$ was mapped to determine the level of the corrosion near the dilatation joints, both on the original area built in the ' 70 s and on the area enlarged in the '90s. Following this mapping, destructive tests were carried out on the concrete

\footnotetext{
* Corresponding author: g.green @mapei.co.za
} 

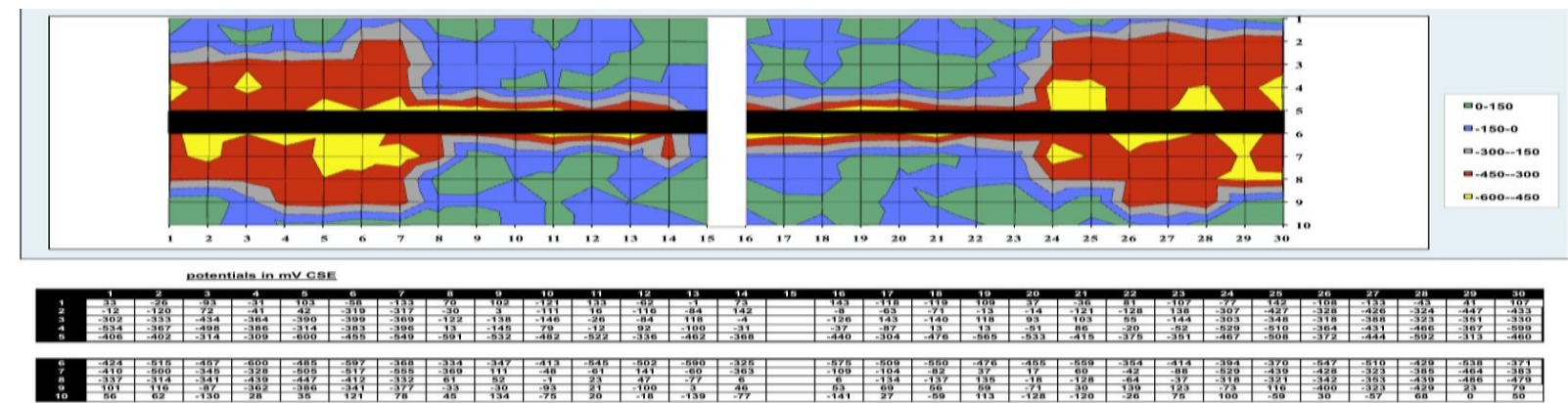

Figure 1. Potential mapping diagram

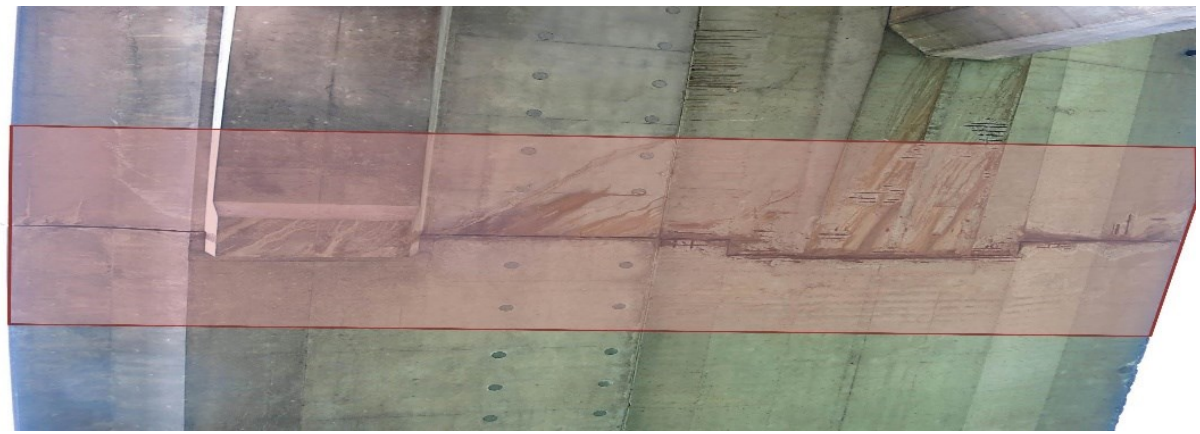

Figure 2. Area subjected to the potential measurement

specimens taken from the affected areas and the levels of carbonation and chloride content were verified. The affected area was approx. $10 \%$ of the total structure's surface area. Following the on-site measurements, it was possible to reproduce, on coloured diagrams using software, the precise identification of the corroded areas. Due to minimal costs of this analysis technique and subsequent results, this method proved to be highly useful for monitoring existing major structures. Regular periodic readings taken with the same measurements over a predetermined time period offered valuable insight and a comprehensive understanding of the corrosion process. The investigation showed an advanced corrosion stage, principally caused by the presence of chlorides that was also confirmed by the laboratory analysis carried out on the concrete samples taken from the structure. In this specific case, the results of the potential mapping showed the following:

1. Chloride penetrated concrete, affecting the reinforcement and leading to corrosion initiation. This process developed quite rapidly.

2. The area of the reinforcement under corrosion was confined within two metres on each side of the joint in the oldest part of the structure (viaduct dating back to the '70s) and within $0,5-1$ metre in the most recent area (enlargement carried out in the '90s).

The visible deterioration of the concrete cover means that the internal reinforcement was already in an advanced corrosion stage and consequently, due to the absence of an adequate anti-corrosion system, lead to extremely high deterioration levels. Due to the above, it was decided to implement a cathodic protection system to prevent future deterioration.

This technique is based on the use of a "sacrificial" material (positive pole or anode) that, when in contact with the reinforcement (negative pole or cathode), oxidises instead of the reinforcement steel.

The current system requires the use of an electric energy source, whilst the galvanic system does not require an external energy source and is able to prevent the corrosion process in the steel reinforcement, prolonging the structural service life. In this specific case a cathodic galvanic system, composed of zinc laminar anode sheets complying with the ISO 12696 standard "Cathodic protection of steel in concrete" was used. This system is easy to apply and ensures a high level of protection against corrosion, thanks to the wide anodic surface of the sheets that is applied, and exposed to the reinforcement to be protected. The advantages observed by using zinc laminar anode sheets, are that an optimal current distribution is achieved with no maintenance costs and additional sacrificial anode sheets can be easily added after installation if needed. By increasing the sheet thickness of the zinc laminar anodes, it is possible to extend the service life of the system for a period of up to 50 years using the galvanic system.

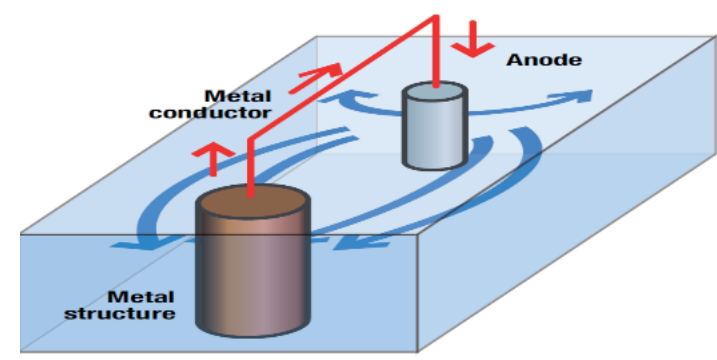

Figure 3. Principle of cathodic protection

In these cases, the sacrificial anode protection system (also called "galvanic") is preferred compared to the impressed current system, due to its low electrochemical 
"driving force" equal to 1 Volt approx., and does not present a danger to high resistant harmonic pre-stressing steels that are inclined to weaken due to hydrogen formation, which could occur when using the impressed current system.

\section{MATERIALS}

After a careful analysis of the deterioration stage and causes, the first operation was to prepare the substrate. This is a fundamental phase to obtain durable repair work.

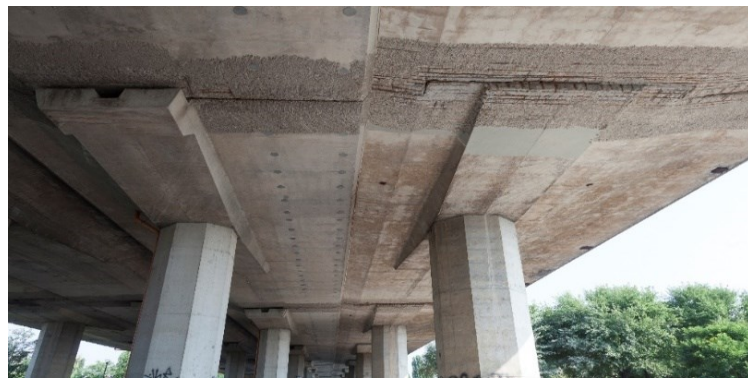

Figure 4. Substrate near the joints prepared by manual hydro scarification

Approximately 2-3 cm of concrete was removed and threaded zinc bars were welded to exposed reinforcing rods.

These bars ( 3 for each joint) work as a connection between the zinc sheet that will be subsequently applied and the reinforcement that is present inside the concrete. After the hydro scarification phase, the surfaces were once again high pressure washed to obtain a saturated dry surface (SDS condition) and the slab was repaired by using a pre-mixed structural mortar. In this specific case,

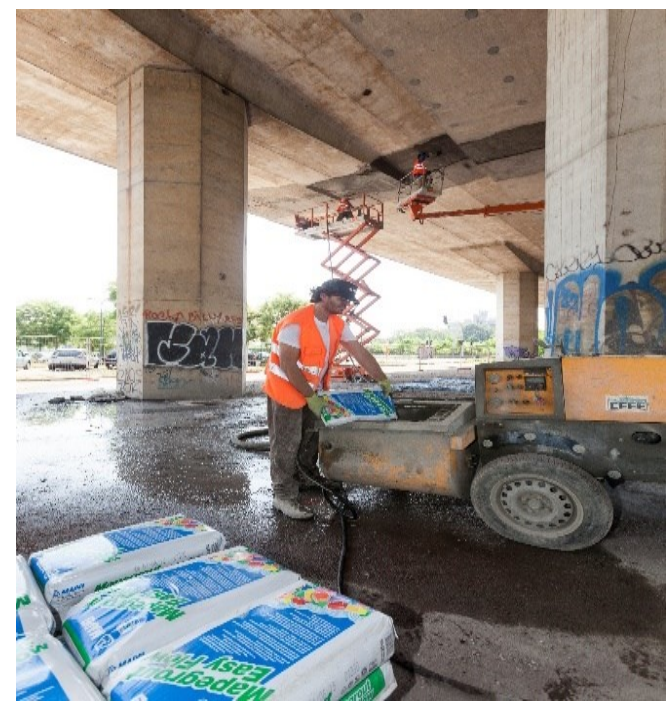

Figure 5. Mixing the flowable structural mortar. Machine equipped with a pre-mixer

a high flow, fibre-reinforced, thixotropic structural mortar was used ( EN 1504-9) (CLASS R4). This mortar can be pumped over long distances and under constant pressure heads and can also be applied on overheads, with no need of formwork placing.

Protection of the reinforcing rods by using a laminar cathodic galvanic system

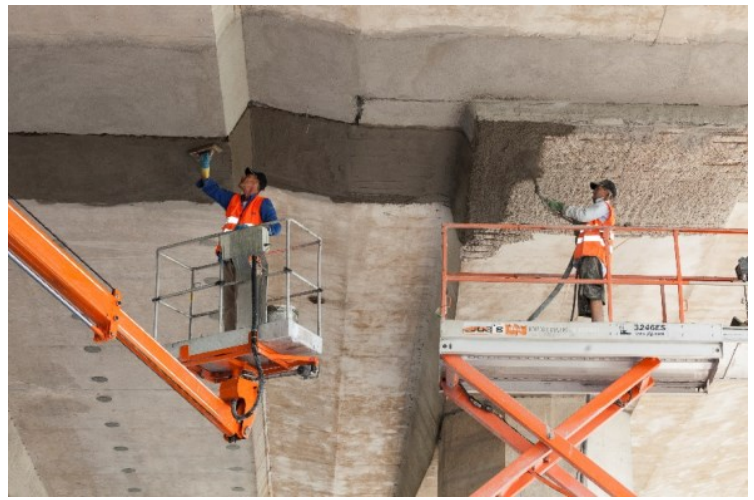

Figure 6. Spray application of high flow mortar-manual floating and finishing.

The anodes used to protect the joints are composed of a pure zinc plate and of an electrolytic gel that also works as an adhesive. After connection, it generates a difference of potential, able to stop the corrosion process and preventing its formation, even in the presence of a particularly aggressive environment.

Self-adhesive laminar anodes, were applied on the repaired concrete surface and connected to the reinforcement by use of threaded zinc bars welded during the substrate preparation phase. 6 strips of self-adhesive laminar anodes were applied, a total of 1,5 $\mathrm{m}$ on both sides

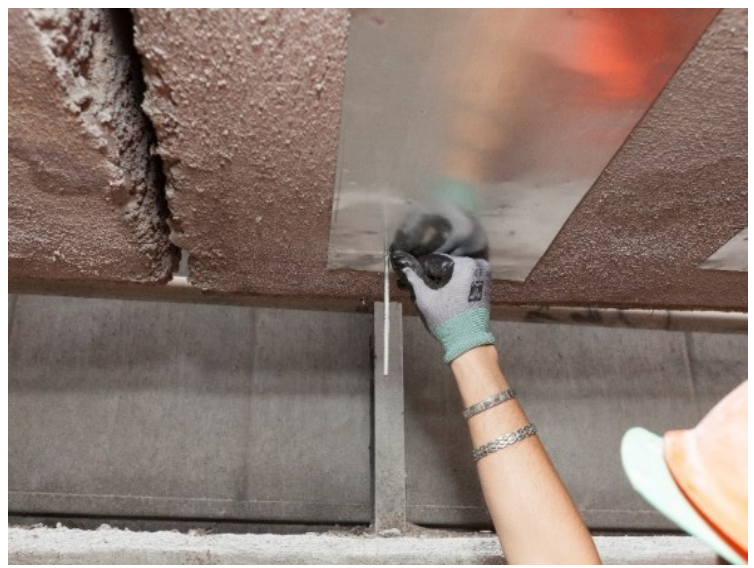

Figure 7. Connection of laminar anodes to threaded bar welded to the pre-existing reinforcement

of the joint.

To ensure the connection between the strips, they were fixed with zinc steel and plastic plugs. Laminar anodes protect the reinforcement against corrosion in compliance with the requirements of the ISO 12696, mentioned in Principle 10 of the EN 1504-9 standard relating to the protection systems for the reinforcement against corrosion.

Final protection 


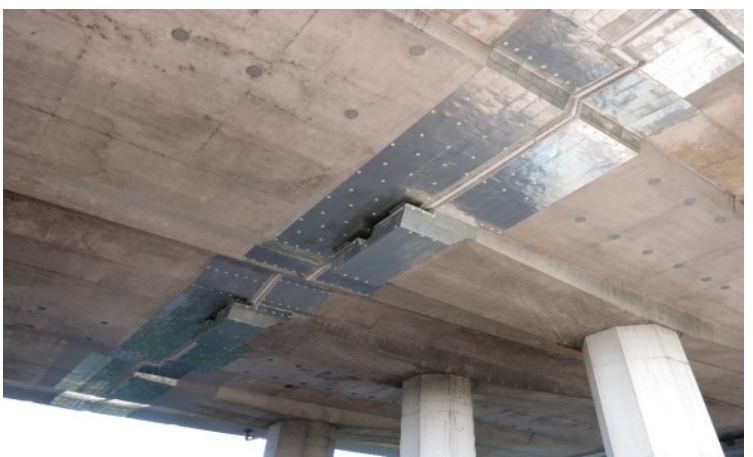

Figure 8. A view of the joint protected with self-adhesive zinc

Once the application of the sheets was completed, the borders near the joint were sealed with an elastic polyurethane sealant, to avoid water seepages under the strips.

To protect the strip and the adjoining concrete, a flexible cementitious mortar able to increase the structural durability, also in presence of aggressive agents, was applied by spraying with a plastering pump equipped with a nozzle suitable for levelling products.

In this way it is possible to waterproof the structural elements against the ingress of new aggressive agents besides levelling the surfaces.

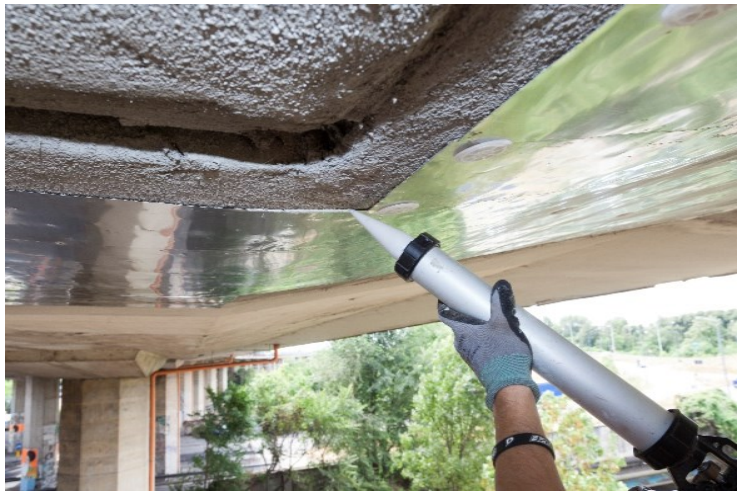

Figure 9. Sealing of the external borders of the strips with elastic polvurethane sealant

The flexible cementitious mortar produces a surface coating that can reduce the penetration of aggressive agents in the concrete.

The cementitious mortar used is a flexible twocomponent cementitious mortar based on cement binders, selected fine-grain aggregates, special additives and synthetic polymers in water dispersion. Due to the high content of synthetic resins and to their quality, the cementitious mortar is resistant to the hardened layer of environmental conditions and is resistant to chemical aggression of salts, sulphates, chlorides and carbon dioxide.

The adhesion of the flexible cementitious mortar complies with the principles defined in EN 1504-9 ("Products and systems for protecting and repairing concrete structures: definitions, requirements, quality control and conformity assessment. General principles for the use of products and systems") and the requirements of EN 1504-2 coating (C) according to principles PI, MC and IR ("Concrete surface protection systems").

Due to the high flexibility of the flexible cementitious mortar, it has a high crack-bridging ability.

\section{TESTS AND RESULTS}

Due to the high flexibility of the flexible cementitious mortar, it has a high crack-bridging ability. Both types of aggression initiate the corrosion in reinforcing steel, resulting in a loss in structural integrity. Carbon dioxide $\left(\mathrm{CO}_{2}\right)$ penetrates the concrete at a rate:

$$
\mathrm{x}=\mathrm{K} \cdot \mathrm{t}^{1 / 2}
$$

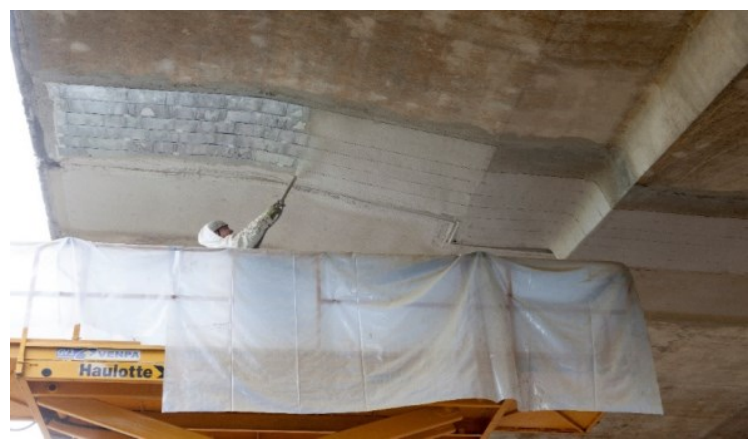

Figure 10. Application by spraying of a flexible cementitious mortar machine equipped with a nozzle suitable for levelling products

where:

$\mathrm{x}$ is the thickness of concrete penetrated by the $\mathrm{CO}_{2}$;

$\mathrm{K}$ is the diffusion coefficient of $\mathrm{CO}_{2}$;

$t$ is the period of exposure to an atmosphere containing $\mathrm{CO}_{2}$.

The value of $\mathrm{K}$ depends mainly on the characteristics of the concrete (type of cement, additives where applicable, water/cement ratio, curing time, etc.) and on the environmental factors (humidity, temperature, concentration of $\mathrm{CO}_{2}$, etc.) and must be identified for each case. Tests carried out by the Società Autostrade per l'Italia (Italian Motorways Society) research laboratories 


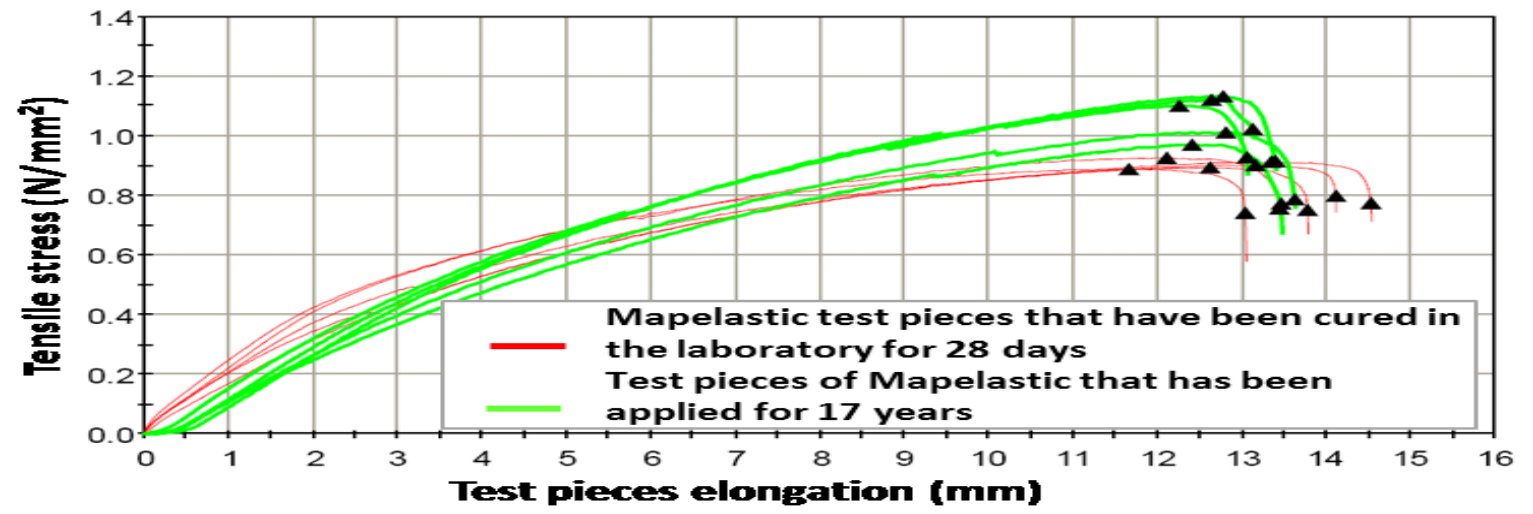

Figure 11. Results of the residual elasticity carried out after 17 years, compared with the results obtained after a 28 days curing

have measured the value of the diffusion coefficient $\mathrm{K}$ on concrete with 0.5 and 0.6 of water/cement ratios.

Results gave an average $\mathrm{K}$ value of 7.6 for concrete with a 0.5 water/cement ratio, and of 8.0 for concrete with a 0.6 water/cement ratio. If we assume a thickness of concrete cover of $\mathrm{x}=30 \mathrm{~mm}$ and these values are applied in the formula $\mathrm{x}=\mathrm{K} \cdot \mathrm{t}^{1 / 2}$, we get:

- $\mathrm{t}_{\text {concrete }}=900 \mathrm{~mm}^{2} / 57.76\left(\mathrm{~mm}^{2}\right.$ year $\left.{ }^{-1}\right) \sim 15.6$ years for concrete with a 0.5 water/cement ratio

- $\mathrm{t}_{\text {concrete }}=900 \mathrm{~mm}^{2} / 64\left(\mathrm{~mm}^{2}\right.$ year $\left.{ }^{-1}\right) \sim 14$ years for concrete with a 0.6 water/cement ratio

where $t$ represents the time required for carbonation to penetrate through all the concrete cover.

The same tests were carried out on concrete samples protected with flexible cementitious mortar, and the results showed $\mathrm{K}$ values of 0.25 to 0.29 .

If we assume an average $\mathrm{K}$ value for the flexible cementitious mortar of $0.27\left(\mathrm{~mm} \cdot\right.$ year $\left.^{1 / 2}\right)$ and then use the formula (1) as above, in this case, where $\mathrm{x}$ is the thickness of the flexible mortar equal to $2 \mathrm{~mm}$, we can affirm that, by applying the flexible cementitious mortar on the surface of concrete, it is possible to increase the durability of structures by providing an efficient barrier against the penetration of $\mathrm{CO}_{2}$ by more than 50 years. If one would like to ensure a protection similar to the one given by the said mortar (50 years), but using a concrete with 0.5 water/cement ratio (with $\mathrm{K}$ equal to $7.6 \mathrm{~mm} \cdot$ year $^{1 / 2}$ ), a concrete cover thickness of over $50 \mathrm{~mm}$ would be necessary. In fact, using the above-mentioned formula, we have:

$$
\mathrm{X}=\mathrm{K} \cdot \mathrm{t}^{1 / 2}=7.6 \cdot 50^{1 / 2} \approx 53.7 \mathrm{~mm}
$$

\section{CONCRETE PROTECTION}

As far as the aggression from chlorides is concerned, according to the Danish certification body COWI (Consultancy within Engineering, Environmental Science and Economics), a $2.5 \mathrm{~mm}$ thick layer of flexible cementitious mortar corresponds to $30 \mathrm{~mm}$ of concrete cover made from concrete with a 0.45 water/cement ratio. The protection is completed by applying an elastomeric protective and decorative paint based on acrylic resins in water dispersion, able to ensure a further protection, besides an excellent chromatic homogeneity. The system composed of the flexible cementitious mortar in conjunction with the use of an elastomeric coating is advantageously used in structures subject to deformations due to dynamic loads and meets the main requirements of EN 1504-2 ("Protection systems for concrete surfaces") for class Coatings (C) complying with the PI principles (Protection against the risk of penetration), $\mathrm{MC}$

(Moisture Control) and IR (Increasing Resistivity) defined by the EN 1504-9.

\section{IN SITU PERFORMANCE}

To prove that the a.m. protection cycle, composed of a flexible cementitious mortar used in conjunction with an elastomeric coating, can keep its mechanical characteristics unaltered over the time, live tests have been carried out on samples of the above system that have been applied on the piles of a viaduct over 17 years ago. In this period the system has been continuously exposed to the atmosphere and have been subjected to repeated freeze-thaw cycles in contact with de-icing salts. To verify that the mechanical properties of the protection system have remained unaltered over the time, flexibility tests have been carried out at our Research \& Development laboratories according to the DIN 53504 modified, and bonding and carbonation tests have been carried out directly in situ.

In the figure 11 above and in the table 1 reported below, the results of the flexibility tests obtained on the 
Table 1: Results of the residual elasticity tests

\begin{tabular}{|c|c|c|c|}
\hline $\begin{array}{c}\text { Maximum tensile strength } \\
\qquad\left(\mathrm{N} / \mathbf{m m}^{2}\right)\end{array}$ & $\begin{array}{c}\text { Elongation to failure } \\
(\%)\end{array}$ & $\begin{array}{l}\text { Thickness } \\
\text { (mm) }\end{array}$ & $\begin{array}{c}\text { Modulus of elasticity } \\
\left(\mathrm{N} / \mathbf{m m}^{2}\right)\end{array}$ \\
\hline \multicolumn{4}{|c|}{ Results obtained on the flexible cementitious mortar that has been cured in laboratory for 28 days } \\
\hline 0,91 & 37,6 & 2,80 & 11,1 \\
\hline 0,90 & 36,8 & 2,65 & 13,5 \\
\hline 0,89 & 36,0 & 2,75 & 13,7 \\
\hline 0,93 & 35,2 & 3,00 & 14,4 \\
\hline 0,89 & 34,0 & 2,98 & 16,5 \\
\hline \multicolumn{4}{|c|}{ Results obtained on the flexible cementitious mortar applied more than 17 years ago } \\
\hline 1,10 & 34,0 & 1,65 & 13,1 \\
\hline 1,01 & 35,6 & 1,92 & 11,1 \\
\hline 1,12 & 34,0 & 1,63 & 12,4 \\
\hline 1,13 & 34,8 & 1,59 & 12,0 \\
\hline 0,97 & 35,2 & 1,90 & 10,6 \\
\hline
\end{tabular}

specimens that have been taken in situ have been compared with the ones obtained on flexible cementitious mortar specimens that have been prepared and cured for 28 days in laboratory. Considering that the flexibility value that is reported on the technical data sheet of the mentioned flexible cementitious mortar, relevant to specimens that have been prepared in laboratory, is $30 \%$, if we analyse the curves reported in the graph and the values of percentage elongation to failure reported in the table, we can conclude that the flexible cementitious mortar used has kept its flexibility unaltered for 17 years. Adhesion tests have been carried out directly in situ and their results are summed up in the table 2 below.
* Note: $\mathrm{DM}=$ detachment of the mortar; RMS = failure of the mortar from the substrate

The obtained adhesion values are, for all the tests that have been carried out, higher than or equal to $0,80 \mathrm{~N} / \mathrm{mm}^{2}$, and turn out to follow the value that is reported on the technical data sheet of the flexible cementitious mortar for specimens that have been prepared and cured in the laboratory and then subjected to freeze-thaw cycles in contact with de-icing salts.

Table 2

\begin{tabular}{|c|c|c|c|}
\hline \multicolumn{3}{|c|}{ Adhesion values of a flexible cementitious mortar applied more than $\mathbf{1 7}$ years ago } \\
\hline Hook No. & $\begin{array}{c}\text { Value that has been } \\
\text { measured by the } \\
\text { instrument }(\mathrm{kN})\end{array}$ & $\begin{array}{r}\text { Adhesion to the } \\
\text { substrate }\left(\mathrm{N} / \mathrm{mm}^{2}\right)\end{array}$ & Failure type \\
\hline 1 & 2,0 & $\mathbf{0 . 8 0}$ & $\begin{array}{c}\text { DM } 60 \% \\
\text { RMS } 40 \%\end{array}$ \\
\hline 2 & 2,4 & $\mathbf{0 . 9 6}$ & $\begin{array}{l}\text { DM } 60 \% \\
\text { RMS } 40 \%\end{array}$ \\
\hline 3 & 2,6 & $\mathbf{1 . 0 4}$ & $\begin{array}{l}\text { DM } 50 \% \\
\text { RMS } 50 \%\end{array}$ \\
\hline 4 & 2,0 & $\mathbf{0 . 8 0}$ & DM 5 \% \\
\hline 5 & 2,1 & $\mathbf{0 . 8 4}$ & RMS 95\% \\
\hline 6 & 2,4 & $\mathbf{0 . 9 6}$ & RMS $100 \%$ \\
\hline
\end{tabular}




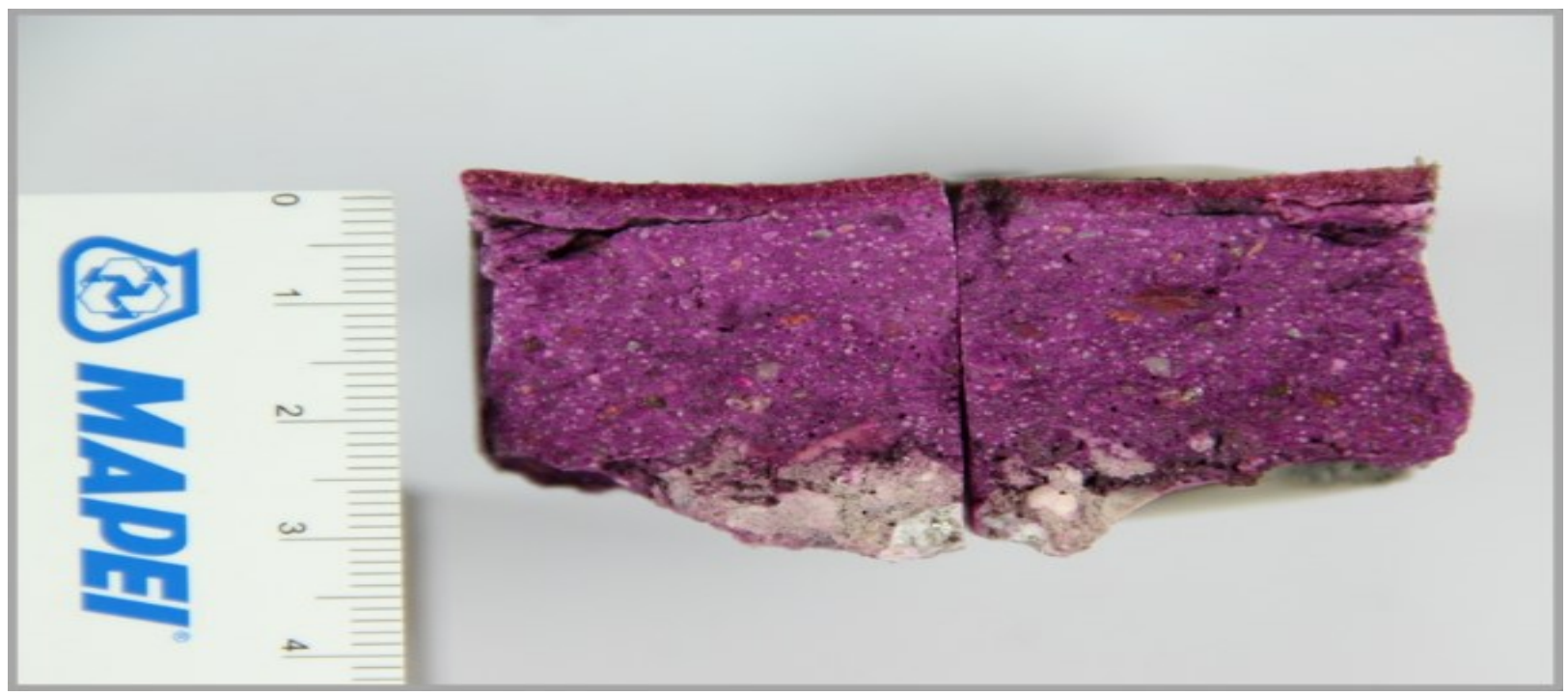

Figure12. Carbonation test with phenolphthalein carried out on specimens that were taken on site

The application of phenolphthalein has shown the total absence of carbonation in the substrate, proving that the system composed of a flexible cementitious mortar used in conjunction with an elastomeric coating effectively prevented the penetration of carbon dioxide for 17 years. Therefore, we can conclude that the above-mentioned protection system eliminates the penetration of carbon dioxide and chlorides, thus protecting the concrete from deterioration and increasing the durability of the protected structures.

\section{CONCLUSION}

The experimental work completed in the laboratory, and in conjunction with field tests conducted, shows how a sacrificial anode system incorporating a flexible cementitious mortar, covered with an elastomeric coating improves the durability of concrete by reducing the penetration of dangerous elements into concrete. This specific case forms part of an ongoing study over the next years to collect further data.

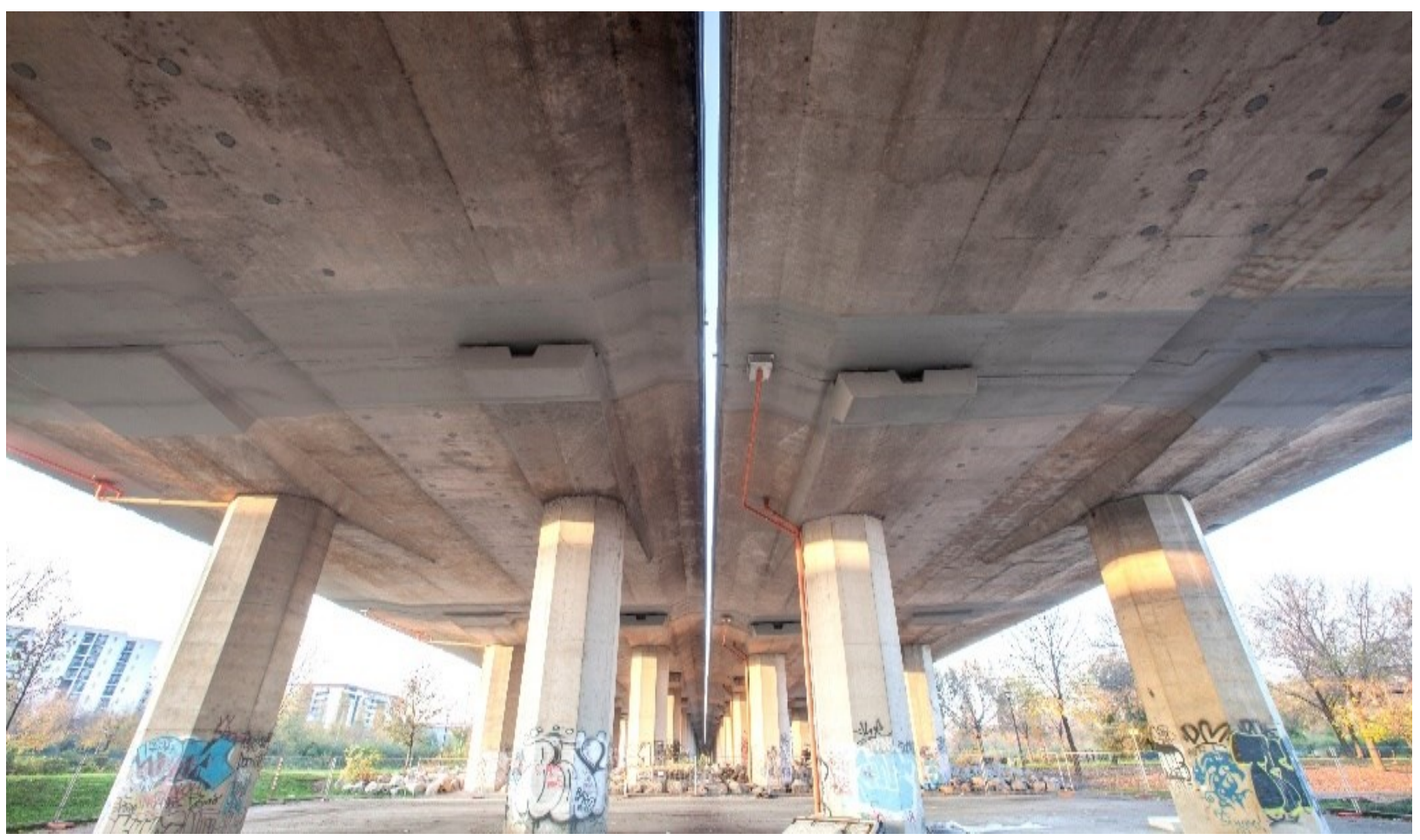

Figure 13. Overview of the completed work 


\section{REFERENCES}

[1] Neville, A.M. (1995), 4th Edition, Longman Group Limited, England UK

[2] L. Bertolini, B. Elsener, P. Pedeferri and R. polder, Corrosion of steel in concrete: prevention, diagnosis, repair, Wiley, Weinheim, 1-409 p, 2003.

[3] Kamimoto, H. Wakasugi, M. \& Miyagawa, T. "Performance of Concrete Coated with Flexible Polymer Cement Mortar" Concrete Under Severe Condition. Enviromental and Loading, Vol 1, 1995, pp.935-944. Editor: K. Sakai, N. Banthia and O.E. Gjorv

[4] L. Creazzi, L. Fedrizzi, P.L. Bonora, K. Bergmeister, "Protection of reinforced concrete structures by means of cementitious and organic coatings with high barrier effect", Proceedings of "Global Construction: Ultimate Concrete Opportunities", Dundee, Scotland July 5th-7th 2005

[5] M.P.M.C. Rodrigues, M.R.N. Costa, A.M. Mendes \& M.I. Eusebio Marques "Effectiveness of surface coatings to protect reinforced concrete in marine environments". Materials and Structures, Vol.33, December 2000, pp.618-626
[6] Coppola, L., Pistolesi, C., Zaffaroni, P., and Collepardi, M. "Ageing Effect on the Properties of Flexible Surface Coating for Concrete Protection”, CI SP 170, pp.1247-1270, 1997

[7] Pfoehler, Zosel, Baumstark "Elastic coating system for the renovation of facades", 1st Trans-Tsman Surface Coatings Conferebce, Gold Coast, Australia, August 1994

[8] C. Maltese, C. Pistolesi, A. Lolli, A. Bravo, T. Cerulli, D. Salvioni "Combined effect of expansive and shrinkage reducing admixtures to obtain stable and durable mortars" Cement and Concrete Research, Vol.35, December 2005, pp.2241-2251

[9] OKAMURA H, OUCHI M. - Application of selfcompacting-concrete in Japan. 3rd International Symposium on Self-Compacting concrete, 2003, Wallevik O, Nielsson Editor, 3-14,Belli M, Mapei IT,Laino, F,Mapei IT 